\title{
Optical physics at university education: the experience and prospects
}

Valerii Kandidov, Nikolai Koroteev, Vladimir Makarov

Valerii P. Kandidov, Nikolai I. Koroteev, Vladimir A. Makarov, "Optical physics at university education: the experience and prospects," Proc. SPIE 3190, Fifth International Topical Meeting on Education and Training in Optics, (8 December 1997); doi: 10.1117/12.294402

SPIE Event: Fifth International Topical Meeting on Education and Training in Optics, 1997, Delft, Netherlands 
Optical physics at university education: the experience and prospects

\author{
V. P. Kandidov, N. I. Koroteev, V. A. Makarov
}

Physics Department \& International Laser Center, M. V. Lomonosov Moscow State University Vorobievy Gory, Moscow 119899, Russia

\begin{abstract}
Development of laser physics has resulted in the fact that the limits of this field have fallen far beyond the scope of conventional physical optics and quantum radiophysics. At present laser physics has virtually transformed into "optical physics" - the field of fundamental and applied physics, which employs specific laser and - more widely - optical approaches in experimental and theoretical investigations. In the present report we outline the concept of teaching in optical physics and discuss methodical problems of education of students at the Department of General Physics and Wave Processes of the Physics Faculty and International Laser Center of the M. V. Lomonosov Moscow State University . The method of teaching in optical physics have resulted from the more than thirty years' experience of work of the Department staff on the training of contemporary highly skilled specialists.
\end{abstract}

Keywords: optical physics, laser physics, diploma work, final report, teaching scheme, "final work of the year"

\title{
1. INTRODUCTION
}

Laser physics and modern optics development has led to the wide extension of this field beyond the frames of traditional physical optics and quantum radiophysics. Laser physics, nonlinear optics, superstrong light field physics, femtosecond optics, nonlinear spectroscopy, polarizational optics and randomly inhomogeneous media optics have formed today a new field in physics named "optical physics". Under the term "optical physics" we mean the part of fundamental and applied physics using specific laser or, let us put it more widely, specific optical and nonlinear optical approaches in experimental and theoretical investigations. The sphere of influence of optical physics expands intensively on chemistry, medicine, biology and other natural sciences. Classical universities in which the academical education in various natural sciences is employed are called to take a leading role in development of methodology of this new field of knowledge.

In the present report we outline the concept of teaching in optical physics and discuss methodical problems of education of students at the Department of General Physics and Wave Processes of the Physics Faculty and International Laser Center of the M. V. Lomonosov Moscow State University

\section{CONCEPT OF EDUCATION}

The education in optical physics in Moscow State University is based on the high-level training of students in general physics and mathematics during the first three years of study at Physics Faculty. These branches of science take the central place in teaching scheme where we reserve more than 2/3 (two thirds) of total education time for them. Due to fundamental knowledge on general and theoretical physics obtained at advanced lecture courses, seminars and colloquiums, laboratory exercises on general physics and physical experimental technique, special practical studies, our students starting from the $3 \mathrm{rd}$ and 4 th years are ready to study the contemporary problems of optical physics. The broad mastery of use of modern mathematics and of computer-based methods of investigations acquired by students at the first years allows our professors to represent the branches of optical physics at the high scientific level. Formation of experts in optical physics is concentrated at the Department of General Physics and Wave Processes of the Physics Faculty and other divisions being parts of International Laser Center of the M. V. Lomonosov Moscow State University. At the end of the 3rd year of study the advanced students have an opportunity to take part into the competition to be educated in optical physics. For the students who won the competition the individual study plan is to be created including general training and laboratory work under direction of leading professors of Moscow University. 
General formation of experts in optical physics is a unified self-according and consequent system of lectures, laboratory work, individual studies and "final work of the year". Nowadays at the Department of General Physics and Wave Processes of the M. V. Lomonosov Moscow State University the whole educational program to form experts capable of creative work in the field of optical physics and adjacent spheres has been developed. This program foresees the formation of specialists ready to conduct an independent research in the different domains of physics of electromagnetic waves, optics, laser physics and in adjacent fields of physics based on modern experimental and theoretical methods.

The program takes in the following scientific subjects forming optical physics: fundamental aspects of light-matter interaction, ultrafast processes in substance, physics of superstrong light fields, nonlinear laser spectroscopy and optical diagnostics, statistical and quantum optics, nonlinear optical interactions and nonlinear wave dynamics, cooperative optical phenomena, X-ray optics, optics of ultrashort pulses, modern femtotechnologies, laser biophysics, chemistry and biomedicine, nonlinear laser acoustics, controlled optical systems, optical methods of information recording, processing and storing. The education on these subjects involves theoretical and experimental research and computer simulation as well.

The important factor of creativity development in future experts is a work in scientific laboratory under professor's direction. During $7^{\text {th }}-9^{\text {th }}$ semesters the scientific work of each student takes in average 2 days a week, but during $10^{\text {th }}-12^{\text {th }}$ semesters student spends practically all his working time in the laboratory. The results of student's scientific work performed during the year are to be presented as "final work of the year" which is to be reviewed and defended publicly at the special commission session consisting of leading professors of Physics Faculty. In the middle of the $5^{\text {th }}$ year of study the students prepare proposals on the subject of scientific investigation for diploma work (master thesis). These proposals been made under the form of "grant application" are to be considered by the head of department and by special commission. In the application one should prove the validity of investigation, give the main purposes of research and estimate its place in the modern science, formulate expected results and make an order on experimental equipment from the funds of the Department. All these facts allow to provide the high level of specialists education. As the result of the work in scientific laboratory under professor's direction student defends diploma work or master degree thesis. Based on materials of more than half students' works carried out during the $4^{\text {th }}, 5^{\text {th }}$ and $6^{\text {th }}$ years of study the papers in leading Russian and foreign journals are published and the reports at various conferences are made.

The graduates of the Department of General Physics and Wave Processes been trained in optical physics are ready to solve complicated experimental, theoretical and application problems of radiophysics, quantum electronics, optics and laser physics. They have to know to:

1. Formulate the problems in the areas of theoretical, experimental and applied physics.

2. Carry out independently fundamental and applied investigations in the fields of radiation interaction with substance, physics of electromagnetic waves, modern optics and laser physics.

3. Develop modern methods of investigations, apply the results of researches to work out the science-intensive technologies.

The high level of education in optical physics is provided by:

1. Highly professional level of scientific and teaching team of the Department of General Physics and Wave Processes of the Physics Faculty and International Laser Center of the M. V. Lomonosov Moscow State University and other scientists from scientific, research and teaching organizations taking part in teaching and investigation collaboration.

2. Experimental base of the Physics Faculty, the Department of General Physics and Wave Processes, International Laser Center of the M. V. Lomonosov Moscow State University and the possibility of using experimental equipment of some scientific and research institutes and laboratories.

3. Active collaboration during many years between M. V. Lomonosov Moscow State University staff and leading Russian and foreign universities and scientific centers.

Professional training of students gives them the possibility to lead scientific investigation on the following subjects:

1. Physics of wave phenomena

2. Laser radiation interaction with substance

3. Nonlinear optics and spectroscopy 
4. Statistical and quantum optics

5. Laser biophysics and biomedicine

6. Applied optics

7. Laser physics

8. Opto-acoustics

and allows them to give courses at universities and other institutes of higher education in Russia.

\section{GENERAL AND SPECIALIZED COURSES IN THE SYSTEM OF EXPERTS TRAINING IN OPTICAL PHYSICS}

Training in optical physics covers the following lines of scientific researches:

1. Fundamental problems of light-matter interaction

2. Ultrafast processes in the substance

3. Nonlinear laser spectroscopy and optical diagnostics

4. Statistical and quantum radiophysics

5. Nonlinear optical interactions, nonlinear wave dynamics

6. Fundamental of laser technology

7. New materials for lasers and nonlinear optics

8. Laser biophysics, chemistry and biomedicine

9. Physics of superstrong laser fields

10. Laser and nonlinear acoustics

11. Cooperative optical phenomena

12. Controlled optical systems

13. Atmosphere optics

14. Optical methods of information recording, processing and storing

15. Optics of ultra-short pulses, femtotechnology

16. X-ray optics

17. Adaptive optics and systems with optical feedback

18. Nonlinear polarizational optics

19. Computer experiment in laser physics

The training of experts on these subjects includes theoretical and experimental investigations and also computer simulations. Education is based on obligatory, alternative and practical courses, work in laboratories, "final work of the year" preparation, participation in scientific seminars of the Department of General Physics and Wave Processes and International Laser Center.

Teaching scheme of Department of General Physics and Wave Processes contains more than 30 original courses on fundamental and modern problems of optical physics. Among them there are courses named "Nonlinear waves and nonlinear optics", "Substance in a strong light field", "Quantum physics of light interaction with substance", "Nonlinear laser spectroscopy", "Complementary chapters of nonlinear laser spectroscopy and femtosecond spectrochronography", "Laser radiation interaction with molecular gases", "Atoms and plasma in super strong light field", "Optics of ultrashort pulses", "Resonance nonlinear optical processes", "Nonlinear polarizational optics", "Statistical and quantum optics", "Random quantum processes in optics", "Optics of randomly inhomogeneous media", "Introduction into the laser physics", "Laser dynamics", "Nonlinear wave dynamics", "Auto wave processes", "Laser diagnostics in biology and medicine". In the teaching-training course called "Experimental laser physics" (duration $108 \mathrm{hr}$.) the students become familiar with the principal ideas of laser and nonlinear optical devices operation, they also obtain practical skills in modern laser set-ups operating. In the course called "Introduction into modern experimental technique" (108 hr.) the students are trained to work with modern experimental set-ups, they master the methods of computer based optical experiment conducting during the course "Numerical methods in modern optics" ( $96 \mathrm{hr}$.). The latter is supported by five practical lessons in display class.

The most part of the courses mentioned above is given according to the traditional scheme involving lectures, seminars, individual tasks, colloquiums, tests and exams. Some courses foresee the student to solve independently rather complicated original tasks. Working on this purpose student could be consulted not only by professor giving this particular course but also by other scientific and teaching staff. The result obtained is to be presented usually as Final 
Report, made under the form corresponding to requirements of manuscript preparation for scientific journals (Instruction to Authors). The teaching-training course "Experimental laser physics" aims at not only giving the students the fundamental knowledge but at teaching them practical skills in research work. That is why this course combines both lectures and practical training with the help of teaching set-ups at the Laser Teaching Laboratory (LTL). This course includes several stages. At first, the students have four short courses (about 4 - 6 hours each course), in which the background material and the main directions of their research are discussed. The mid-term consists in 7 days experimental work at the LTL (one day a week, 6 hours every day). Each student should perform all the experimental work proposed in LTL, i.e. seven laboratory experiments (continuous wave and Q-switched laser, picosecond laser, optical harmonics generation, optical parametric oscillator, holography set-up, CARS-spectrometer, optical modulators).

An individual workshop with a teacher includes preliminary discussion of one of the problems and ways of their solution, conducting the experiment, analyzing the experimental data and the final discussion. At the end of the term the students shall present a Final report, in which they show the results of all laboratory experiments and give a short talk on one of the investigated problems. This a round table discussion ends the course. The most advanced students are suggested to carry out an independent research using the LTL equipment and set-ups.

\section{PROGRAM OF OPTICAL EDUCATION}

On the $3^{\text {rd }}$ and $4^{\text {th }}$ years of study (this corresponds to $6^{\text {th }}-8^{\text {th }}$ semesters) the obligatory lecture courses are given on which the exams and test passing is necessary to be educated in optical physics and also the alternative courses marked by asterisks.

$$
6^{\text {th }} \text { semester }
$$

Oscillation theory ( $32 \mathrm{hr}$., exam)

Principals of quantum electronics ( $32 \mathrm{hr}$., test)

$7^{\text {th }}$ semester

Computation physics ( $54 \mathrm{hr} .$, exam)

Waves theory (54 hr., exam)

Principals of electronics ( $36 \mathrm{hr} .$, test)

Experimental laser physics (lectures and laboratory work $108 \mathrm{hr}$., test)

\section{$8^{\text {th }}$ semester}

Introduction into the statistical radiophysics and optics ( $32 \mathrm{hr} .$, exam)

Nonlinear optics (48 hr., exam)

Substance in a strong light field ( $32 \mathrm{hr} .$, test)

Introduction into modern experimental technique (lectures and laboratory work $108 \mathrm{hr}$., test.)

Practical course on specialization ( $96 \mathrm{hr} .$, test)

"Final work of the year" (exam)

*Lasers dynamics ( $32 \mathrm{hr}$. , test)

*Laser diagnostics in biology and medicine ( $32 \mathrm{hr} .$, test)

*Controlled optical systems ( $32 \mathrm{hr}$., test)

*Numerical methods in modern physics (96 hr., test)

$$
9^{\text {th }}-12^{\text {th }} \text { semester }
$$

After the students been accepted to study for Master Degree the education continues according to the individual scheme been confirmed by the Head of Department. Individual teaching scheme is formed on the basis of typical plan on Master Degree training at Physics Faculty. This plan includes the study on certain obligatory disciplines taken from the list given below, Final Reports preparation and presentation and Master Degree thesis defending.

1. Physics of condensed phases ( $36 \mathrm{hr}$., exam)

2. Nonlinear laser spectroscopy ( $36 \mathrm{hr}$., exam)

3. Statistical and quantum optics ( $36 \mathrm{hr} .$, exam)

4. "Final work of the year" (exam)

5. Master thesis (or diploma work) (exam)

6. *Coherent interactions in optics ( $36 \mathrm{hr}$., test)

7. *Auto wave processes ( $36 \mathrm{hr}$., test)

8. *Optics of ultra short pulses ( $36 \mathrm{hr} .$, test)

9. *Laser radiation interaction with molecular gases ( $36 \mathrm{hr}$., test) 
10. *Data bases (36 hr., test)

11. *Stability of multi-particles systems ( $36 \mathrm{hr}$., test)

12. *Random quantum processes in radiophysics ( $32 \mathrm{hr}$., exam)

13. *Nonlinear polarizational optics ( $32 \mathrm{hr}$., exam)

14. *Laser-induced instability and phase transitions (Laser synergetic) ( $32 \mathrm{hr}$., exam)

15. * Optics of randomly inhomogeneous media ( $32 \mathrm{hr}$., exam)

16. *Biomolecules dynamics; Mathematical modeling and laser spectroscopy ( $32 \mathrm{hr}$., test)

17. *Atomic particles and plasma in super strong light field ( $32 \mathrm{hr}$., test)

18. *Nonlinear optics of wave guides ( $32 \mathrm{hr}$., test)

19. *Resonance nonlinear optical phenomena ( $32 \mathrm{hr} .$, test)

20. Modern problems of laser physics $(50 \mathrm{hr}$., test. The course is given by invited leading experts from foreign countries and Russia within the scope of Higher Laser School of International Laser Center of Moscow State University).

The practical studies of scientific work (698 hr.) include scientific and research work in laboratory according to the individual schedule of future Master and also participation in the scientific seminars and conferences. To perform the master thesis (diploma work) one gives $576 \mathrm{hr}$. The defending of master thesis (or diploma work) goes in the frames of free scientific discussion with obligatory review to be made and the presentation of scientific chief to be performed. Such a discussion allows to define the level of specialist qualification in the field of optical physics. The essential part of diploma works represents serious scientific investigations with interesting results obtained. Based on the materials of most diploma works and master thesis the papers in leading Russian and foreign scientific journals are published and the reports on various conferences and symposiums are made.

\section{CONCLUSIONS}

The methodology of optical physics education is the result of more than 30 years work experience of Physics Faculty, the Department of General Physics and Wave Processes, International Laser Center of the M. V. Lomonosov Moscow State University staff in formation of contemporary highly-qualified specialists ${ }^{1-4}$. The system of their training has received an acknowledgment all over the world. The Department graduates are working and studying as postgraduates in the most respectful universities and scientific laboratories in Russia, Europe, USA and other countries. Among our graduates there are scientists been favored by Russian and international scientific prizes and awards.

\section{ACKNOWLEDGMENTS}

The authors would like to note the great contribution of Profs. A. V. Andreev, A. S. Chirkin, V. I. Emel'yanov, V. T. Platonenko, Yu. M. Romanovsky, V. I. Shmalhausen, V. V. Shuvalov and Drs. S. S. Chesnokov, A. Yu. Chikishev, K. N. Drabovich, V. M. Gordienko, B. A. Grishanin, T. M. Il'inova, A. A. Lukashev, A. A. Karabutov, S. A. Magnitskii, V. B. Morozov, S. Yu. Nikitin, M. S. Poliakova, Yu. V. Ponomarev, A. V. Priezzhev, V. I. Priyalkin, A. B. Savel'ev, A. P. Shkurinov, S. A. Shlenov, V. S. Solomatin, V. N. Zadkov B. V. Zhdanov and A. M. Zheltikov to education of students in the field of optical physics.

\section{REFERENCES}

1. N. I. Koroteev. Laser Research and Educational Activity at M.V.Lomonosov Moscow State University. Proc. of the Workshop "Exploring the Opportunities for Cooperative Research" AL BED, Orlando FL, pp. 1-30, 1994.

2. V. N. Zadkov, N. I. Koroteev. How to manage continuing education and retraining programs on optical physics and laser technology at a university: Moscow State experience. Proc. SPIE, 2525, 553-565 (1995).

3. V. P. Kandidov, N. I. Koroteev, V. A. Makarov. Optical Education of Mathematical Student at M. V. Lomonosov Moscow State University. Proc. SPIE, 2525, 483-488, (1995).

4. V. P. Kandidov, S. A. Shlenov. Optics for Mathematics. Proc. Intern. Conf. Education and Training in Optics, Hungary, Pecs, pp. 81-87, 1993. 